\title{
Size dependent optical characteristics of chemically deposited nanostructured ZnS thin films
}

\author{
A U UBALE*, V S SANGAWAR and D K KULKARNI ${ }^{\dagger}$ \\ Department of Physics, Govt. Vidarbha Institute of Science and Humanities, Amravati 444 604, India \\ ${ }^{\dagger}$ Department of Physics, Institute of Science, Nagpur 440 001, India
}

MS received 19 December 2006; revised 26 February 2007

\begin{abstract}
ZnS thin films of different thicknesses were prepared by chemical bath deposition using thiourea and zinc acetate as $\mathrm{S}^{2-}$ and $\mathrm{Zn}^{2+}$ source. The effect of film thickness on the optical and structural properties was studied. The optical absorption studies in the wavelength range $250-750 \mathrm{~nm}$ show that band gap energy of $\mathrm{ZnS}$ increases from 3.68-4.10 eV as thickness varied from $332-76 \mathrm{~nm}$. The structural estimation shows variation in grain size from $6 \cdot 9-17 \cdot 8 \mathrm{~nm}$ with thickness. The thermoemf measurement indicates that films prepared by this method are of $n$-type.
\end{abstract}

Keywords. Thin film; ZnS; CBD method; optical properties.

\section{Introduction}

Chemical bath deposition is a well known deposition process for some chalcogenides such as $\mathrm{Zn}, \mathrm{Co}, \mathrm{Cd}, \mathrm{Hg}$, $\mathrm{Pb}$, sulphides and selenides (Mane and Lokhande 2000). Zinc sulfide is an important semiconductor material with large band gap $(\sim 3.5 \mathrm{eV})$, high refractive index $(2.35$ at $632 \mathrm{~nm}$ ), high effective dielectric constant ( 9 at $1 \mathrm{MHz})$ and wide wavelength passband $(0 \cdot 4-13 \mu \mathrm{m})$. Its optical properties make it useful as a filter, reflector and planar wave guide (Mach and Muller 1982). It has a vast potential for use in optoelectronics and in electroluminescent devices (Mika et al 1988). Several methods have been applied to grow $\mathrm{ZnS}$ thin films by different workers such as sputtering (Cattell and Cullis 1982), molecular beam epitaxy (Tong et al 1996), layerwise chemisorption (Klechkovskaya et al 1989), chemical deposition (Fukarova et al 1997), chemical vapour deposition (Nicolau and Menand 1988; Kashani 1996) and liquid phase atomic layer expitaxy (Lindroos et al 1994). Every thin film deposition technique has its own advantages and disadvantages. In the present case chemical bath deposition technique (CBD) is studied for deposition of $\mathrm{ZnS}$ thin films since it is simple, relatively less expensive and convenient for large area deposition. The effect of preparative parameters like $\mathrm{pH}$ and temperature on deposition process has also been reported in this paper.

In recent years, interest in the physical properties of thin films has considerably increased. New effects can appear in the film states that are not observed in the bulk

*Author for correspondence (ashokuu@yahoo.com) samples (Lokhande et al 1997). When the dimensions of the film are comparable with some characteristic length such as the electron mean free path or the de Broglie wavelength of the electron, the physical properties start to become functions of the film size. In particular, when the thickness of the film is of the order of the de Broglie wavelength of the electron, quantization of the electron levels due to size of the film introduces new size effects. In the present investigation, to study such size dependent properties, the thickness of $\mathrm{ZnS}$ film was varied by changing the deposition time period and its effect on bandgap energy, thermoemf and grain size, studied.

\section{Experimental}

A simple chemical bath deposition (CBD) method was employed to deposit $\mathrm{ZnS}$ thin films onto glass substrates using thiourea as sulfide ion source and zinc acetate as zinc ion source in alkaline bath. For the preparation of $\mathrm{ZnS}$ thin films, $0 \cdot 2 \mathrm{M}$ zinc acetate solution was taken in a beaker and an equal volume of $0 \cdot 2 \mathrm{M}$ thiourea solution was added. Ammonia solution was added slowly to form the complex and $\mathrm{pH}$ was adjusted between 9 and 10 . The solution was stirred for a few seconds and transferred to another beaker containing glass substrates. The solution was kept at $303 \mathrm{~K}$. Substrate cleaning plays an important role in the deposition of thin films. Commercially available glass microslides of dimensions $26 \times 76 \times 2 \mathrm{~mm}$ were boiled in chromic acid for $2 \mathrm{~h}$ and kept in it for $12 \mathrm{~h}$ washed with detergent, and finally rinsed in acetone before use. The films with different thicknesses were obtained by varying the deposition time period. Amongst 
the different methods for measuring thickness, two methods viz. weight difference method and Fizzau's method, were used to measure the thickness. The grain size calculations were carried out by using XRD studies on Philips PW1710 Diffractometer. The optical absorption studies were carried out using Hitachi-330, Japan, to calculate optical band gap.

\section{Results and discussion}

\subsection{Reaction mechanism}

$\mathrm{ZnS}$ thin films were prepared by decomposition of thiourea in an alkaline solution containing a zinc salt. The reaction mechanism for deposition of $\mathrm{ZnS}$ films has been reported earlier by Ubale and Kulkarni (2005). In aqueous solution zinc acetate dissociates to give $\mathrm{Zn}^{2+}$ ions. Hydrolysis of ammonia in water gives $\mathrm{OH}^{-}$ions, which forms complex $\mathrm{Zn}\left(\mathrm{NH}_{3}\right)_{4}^{2+}$. Thiourea in alkaline medium acts as an $\mathrm{S}^{2-}$ ion source. In short, the reaction for the process is

$$
\begin{aligned}
& \mathrm{Zn}\left(\mathrm{NH}_{3}\right)_{4}^{2+}+\mathrm{SC}\left(\mathrm{NH}_{2}\right)_{2}+2 \mathrm{OH}^{-} \rightarrow \\
& \mathrm{ZnS} \downarrow+4 \mathrm{NH}_{3}+\mathrm{CH}_{2} \mathrm{~N}_{2}+2 \mathrm{H}_{2} \mathrm{O} .
\end{aligned}
$$

\subsection{Effect of preparative parameters}

The effect of preparative parameters such as $\mathrm{pH}$ of the reaction mixture and deposition temperature was studied. Figure 1 shows variation of film thickness with deposition time at 303 and $318 \mathrm{~K}$ temperatures. The deposition process clearly shows two different growth phases: quasilinear phase and saturation phase. Many researchers have observed similar growth rate dependence on temperature for $\mathrm{CdS}$ and $\mathrm{Sb}_{2} \mathrm{~S}_{3}$ film by CBD (Lincot and Vedel 1991; Dona and Herrero 1992; Savadogo and Mandal 1992). It can be seen from this figure that in the initial stage of the process, the film thickness increases at a fast rate and then growth rate decreases resulting in a terminal thickness. The average growth rate at $303 \mathrm{~K}$ is slow $(18.6 \mathrm{~nm} / \mathrm{h})$ and terminal thickness of $\sim 330 \mathrm{~nm}$ is attained after $\sim 20 \mathrm{~h}$. However, the average growth rate at $318 \mathrm{~K}$ is higher $(20.20 \mathrm{~nm} / \mathrm{h})$ and terminal thickness of $\sim 310 \mathrm{~nm}$ is reached after $\sim 17 \mathrm{~h}$.

Figure 2 shows variation of $\mathrm{ZnS}$ film thickness with deposition time for different $\mathrm{NH}_{3}$ concentrations i.e. for different $\mathrm{pH}$ values. $\mathrm{NH}_{3}$ acts as a complexing agent as well as $\mathrm{pH}$ enhancer to the $\mathrm{Zn}$ salt solution. It was found that, for low $\mathrm{NH}_{3}$ concentration, i.e. when the $\mathrm{OH}^{-}$concentration is low, the $\mathrm{Zn}^{2+}$ ion concentration in the solution is more due to less complexation of $\mathrm{Zn}^{2+}$ ions, and the homogeneous process takes place at slow rate resulting in a lower terminal thickness. At high $\mathrm{NH}_{3}$ concentration, availability of $\mathrm{Zn}^{2+}$ ions is low due to higher complexation, but $\mathrm{S}^{2-}$ ion concentration is more that gives higher deposition rate.

\subsection{Grain size studies}

The XRD pattern of $\mathrm{ZnS}$ thin film of thickness, $332 \mathrm{~nm}$ (figure 3 ) shows that films are polycrystalline in nature. Comparison with ASTM data for ZnS shows that the material is $\mathrm{ZnS}$ with hexagonal structure (ASTM data file).

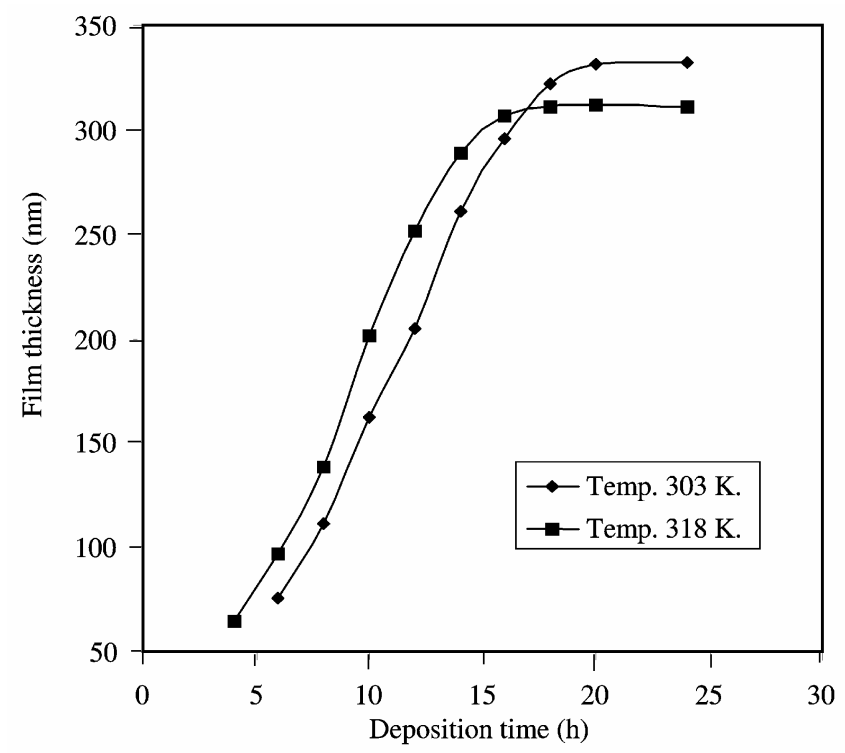

Figure 1. Variation of $\mathrm{ZnS}$ film thickness with deposition time at temperatures 303 and $318 \mathrm{~K}$.

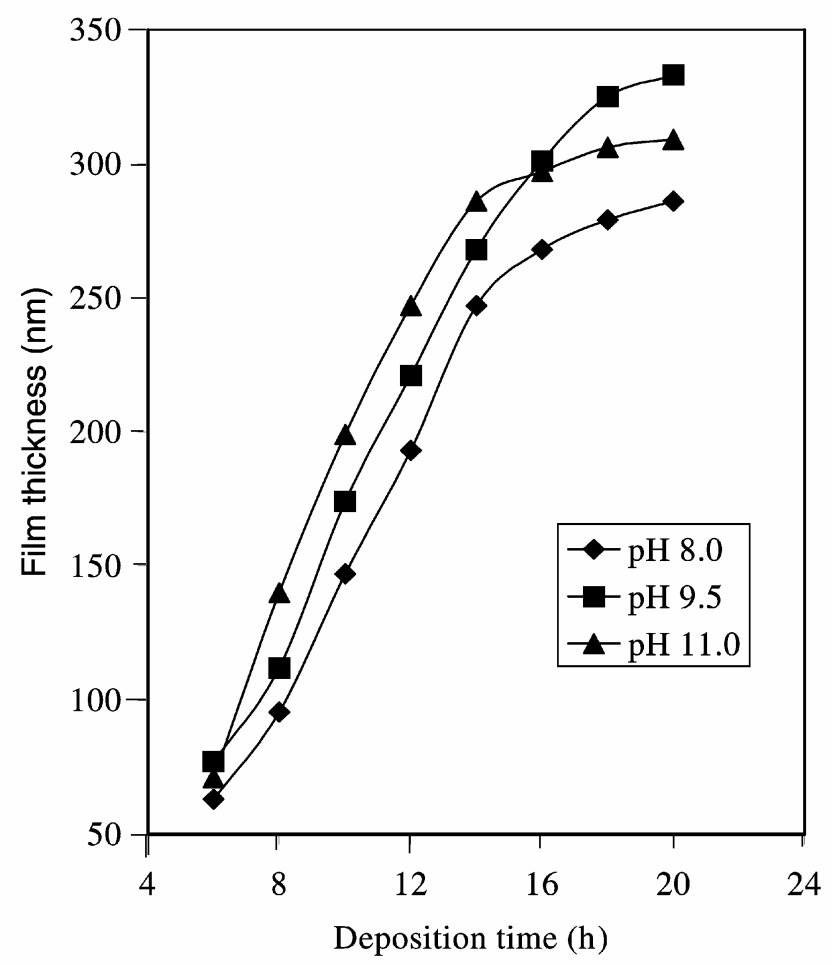

Figure 2. Variation of $\mathrm{ZnS}$ film thickness with deposition time for different $\mathrm{pH}$ values. 
In order to determine grain size of $\mathrm{ZnS}$ particles by considering a common plane (210), slow scan between angle $75^{\circ}$ and $80^{\circ}$ was carried out with a step of $0.02^{\circ} / 10 \mathrm{~s}$ for the films with different thicknesses as shown in figure 4 .

The crystallite size is calculated using Scherrer's formula

$$
d=\lambda / \beta \cos \theta,
$$

where $\lambda$ is the wavelength used (1.54 $\AA$ ), $\beta$ the angular line width at half maximum intensity in radians and $\theta$ the Bragg's angle.

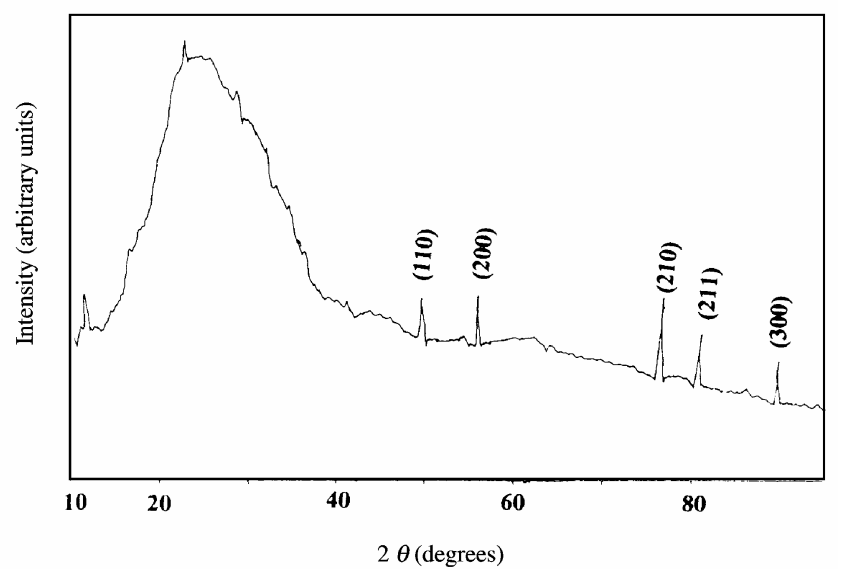

Figure 3. X-ray diffraction pattern of $\mathrm{ZnS}$ thin film of thickness, $332 \mathrm{~nm}$

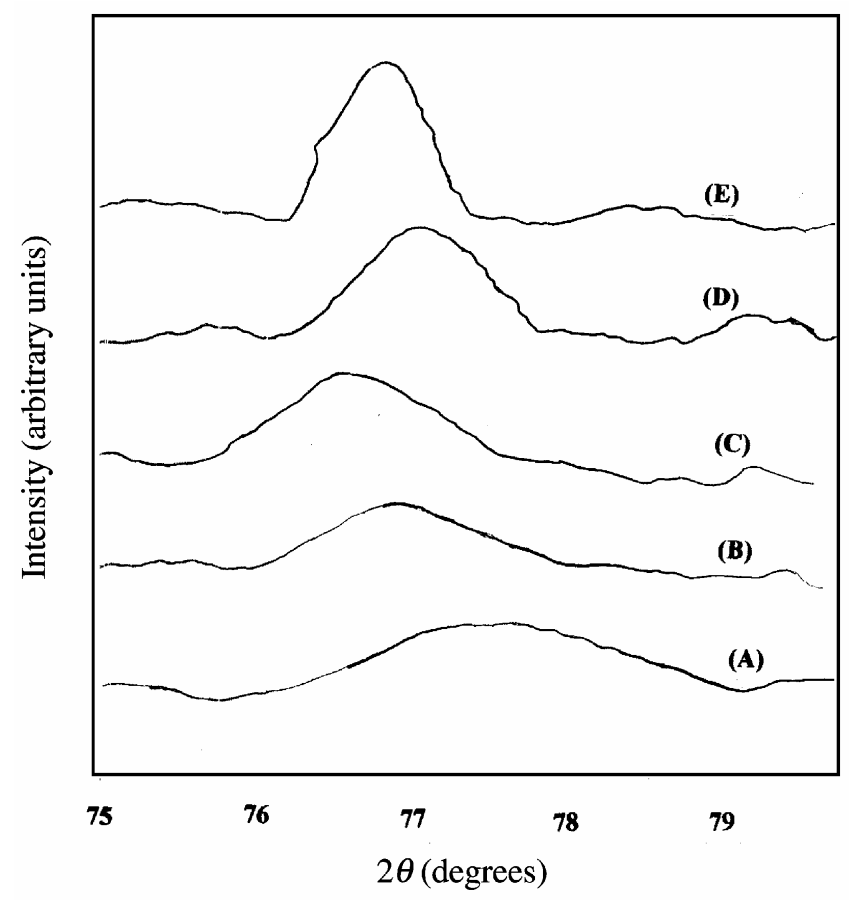

Figure 4. XRD patterns (slow scan between 75 and $80^{\circ}$ ) of ZnS thin films of different thicknesses: (A) $76 \mathrm{~nm}$, (B) $141 \mathrm{~nm}$, (C) $207 \mathrm{~nm}$, (D) $272 \mathrm{~nm}$ and (E) $332 \mathrm{~nm}$.
The variation of grain size with film thickness is shown in figure 5 . The grain size was changed from $6 \cdot 9-17.8 \mathrm{~nm}$ as film thickness was changed from $76-332 \mathrm{~nm}$. This change supports the size effects observed in semiconductors.

\subsection{Thermoemf measurements}

The dependence of thermoemf on temperature and thickness is shown in figure 6 . The temperature difference

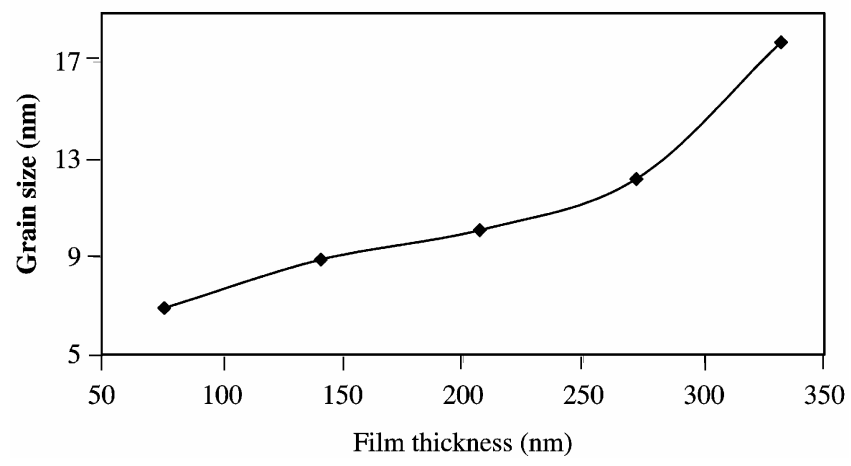

Figure 5. Variation of grain size of $\mathrm{ZnS}$ material with film thickness.

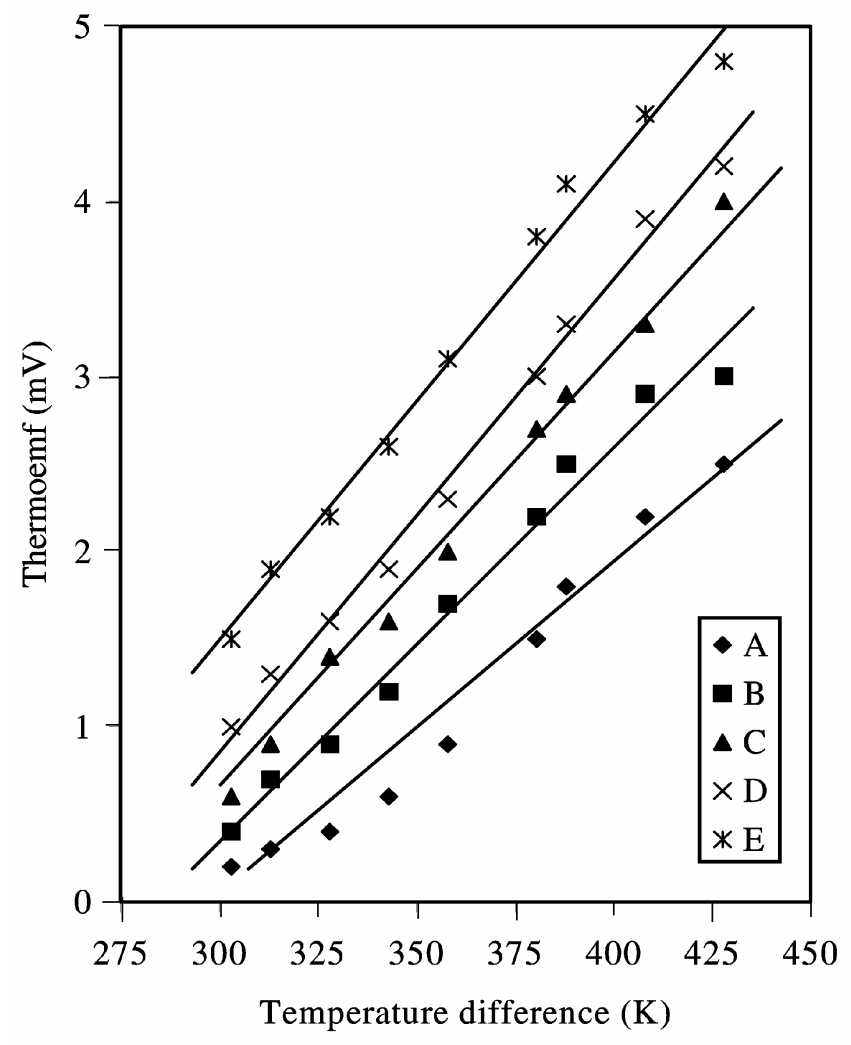

Figure 6. Plots of thermoemf vs temperature difference for different thicknesses of $\mathrm{ZnS}$ films: (A) $76 \mathrm{~nm}$, (B) $141 \mathrm{~nm}$, (C) $207 \mathrm{~nm}$, (D) $272 \mathrm{~nm}$ and (E) $332 \mathrm{~nm}$. 
between the ends of sample causes transport of carriers from hot to cold end and thus creates electric field, which

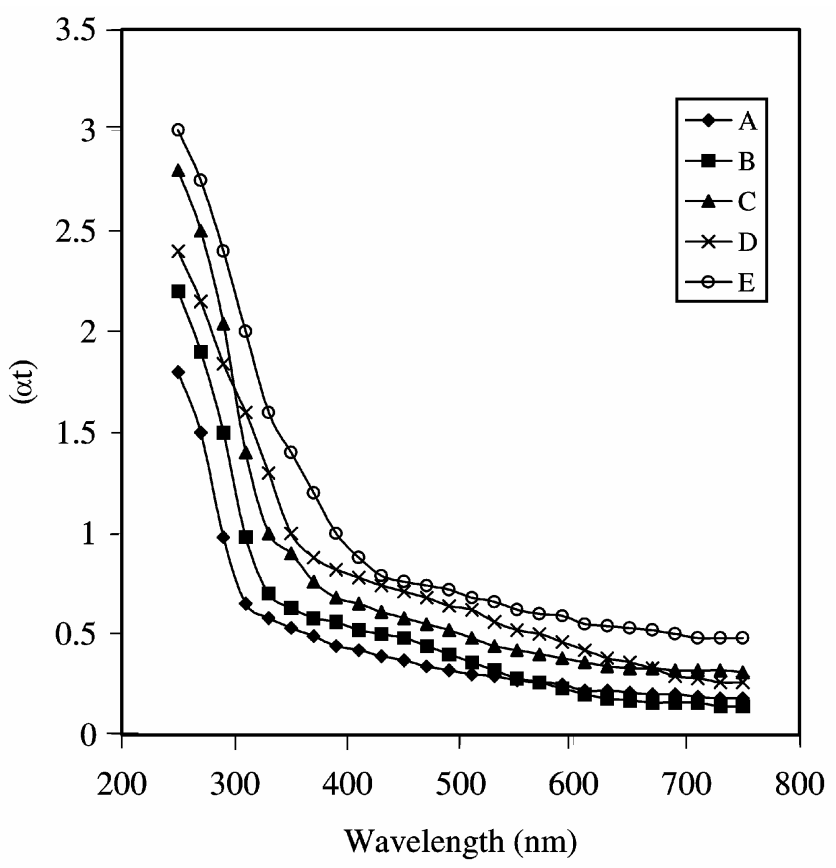

Figure 7. Plots of optical absorption $(\alpha t)$ vs wavelength (nm) for different thicknesses of $\mathrm{ZnS}$ film: (A) $76 \mathrm{~nm}$, (B) $141 \mathrm{~nm}$, (C) $207 \mathrm{~nm}$, (D) $272 \mathrm{~nm}$ and (E) $332 \mathrm{~nm}$.

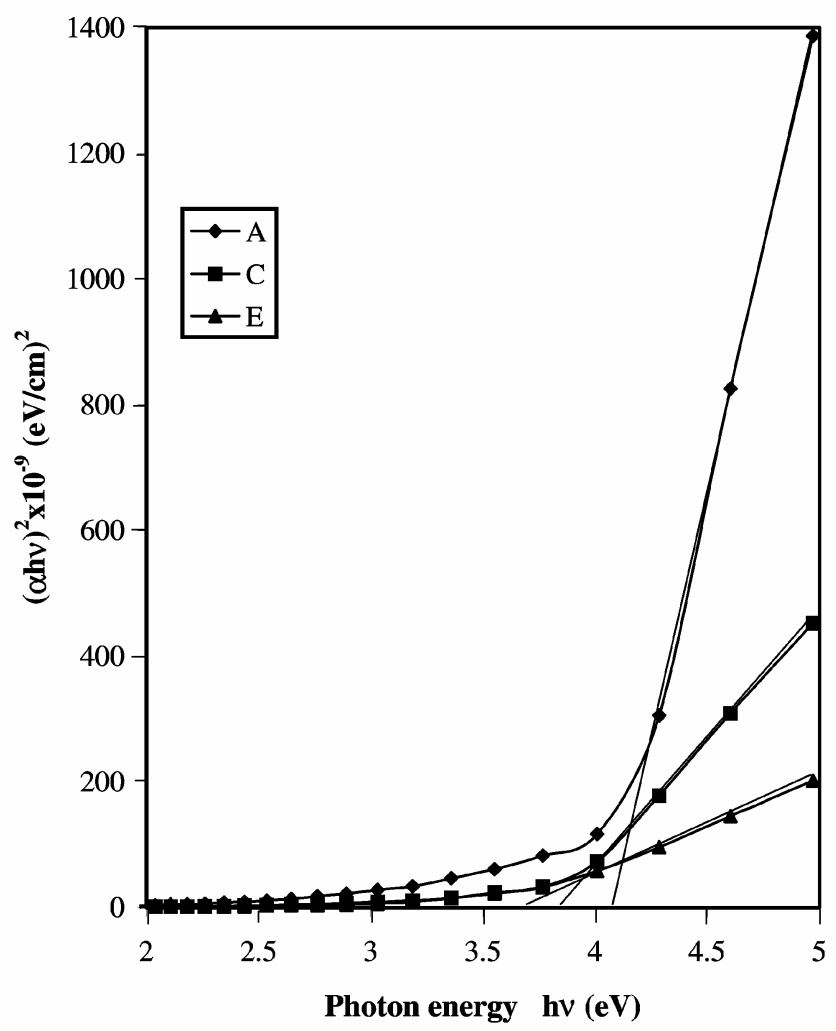

Figure 8. Plots of $(\alpha h v)^{-2}$ vs $h v$ for $\mathrm{ZnS}$ film with thicknesses: (A) $76 \mathrm{~nm}$, (C) $207 \mathrm{~nm}$ and (E) $332 \mathrm{~nm}$.

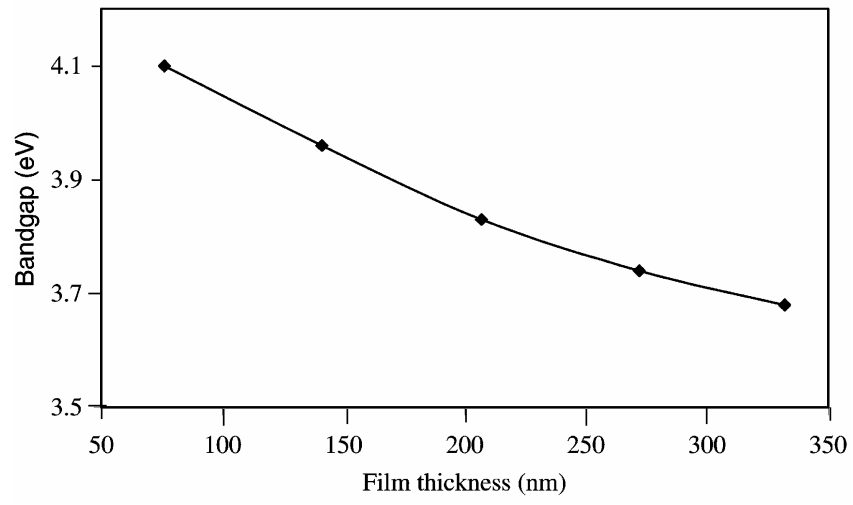

Figure 9. Variation of optical band gap, $E_{\mathrm{g}}(\mathrm{eV})$, with $\mathrm{ZnS}$ film thickness (nm).

gives thermal voltage. The plots show that voltage developed across the junction increases with temperature difference, which is due to rise in concentration and mobility of the charge carriers (Lokhande et al 1998). This thermally generated voltage is directly proportional to the temperature difference created across the semiconductor. In the present work, it was found that films are of $n$-type.

\subsection{Optical absorption studies}

Study of materials by means of optical absorption provides a simple method for explaining some features concerning the band structure of materials. In the present investigation, optical absorption (figure 7) in $\mathrm{ZnS}$ films with different film thicknesses was studied in the wavelength range $250-750 \mathrm{~nm}$. The nature of transition (direct or indirect) is determined by using the relation

$$
\alpha=\frac{A\left(h v-E_{\mathrm{g}}\right)^{n}}{h v}
$$

where $h v$ is the photon energy, $E_{\mathrm{g}}$ the band gap energy, $A$ and $n$ are constants. For allowed direct transition, $n=1 / 2$ and for allowed indirect transition, $n=2$.

The plots of $(\alpha h v)^{2}$ vs $h v$ are shown in figure 8, for $\mathrm{ZnS}$ films. The linear nature of the plots indicates the existence of direct transitions. It is seen that band gap was increased from $3 \cdot 68-4 \cdot 10 \mathrm{eV}$ as thickness was reduced from $332-76 \mathrm{~nm}$. The value of $E_{\mathrm{g}}$ for bulk $\mathrm{ZnS}$ is $3.7 \mathrm{eV}$ (Dube 1960). Figure 9 shows variation of $E_{\mathrm{g}}$ with film thickness (Lokhande et al 1997).

\section{Conclusions}

In this paper we have reported the thickness dependent optical properties of $\mathrm{ZnS}$ thin films deposited in alkaline medium by chemical bath deposition. The thermoelectric power measurement shows that the films were of $n$-type. 
When film thickness is changed from $76-332 \mathrm{~nm}$, the grain size was changed from $6 \cdot 9-17 \cdot 8 \mathrm{~nm}$, with change in optical band gap from $4 \cdot 10-3 \cdot 68 \mathrm{eV}$ (i.e. $0 \cdot 42 \mathrm{eV}$ shift).

\section{Acknowledgement}

The authors are thankful to the University Grants Commission, WRO, Pune, for financial support under the project (No. F47-15/2003).

\section{References}

ASTM Diffraction data file card, No. 12-688, 10-434, and 5-0492 Cattell A F and Cullis A G 1982 Thin Solid Films 92211

Dona J M and Herrero J 1992 This Journal 1392810

Dube R H 1960 Photoconductivity of solids (New York: Wiley) p. 233

Fukarova M, Juruskovska, Ristov M and Andonow A 1997 Thin Solid Films 299149
Kashani H 1996 Thin Solid Films 28850

Klechkovskaya V V, Maslov V N and Murad M B 1989 Sov. Phys. Crystallogr. 34105

Lincot D and Vedel J 1991 Proceedings of $10^{\text {th }}$ European photovoltaic solar energy conference, Lisbon (Dordrecht, The Netherlands: Kluwer Academic Publishers) p. 931

Lindroos S, Kanniainen T and Leskela M 1994 Appl. Surf. Sci. $\mathbf{7 5 7 0}$

Lokhande C D, Ubale A U and Patil P S 1997 Thin Solid Films 3021

Lokhande C D, Yermune V S and Pawar S H 1998 J. Electrochem. Soc. 1351852

Mach R and Muller G O 1982 Phys. Status Solidi A69 11

Mane R S and Lokhande C D 2000 Thin Solid Films 651

Mika P V and Lindroos S 1988 Appl. Surf. Sci. 136131

Nicolau Y F and Menand J C 1988 J. Cryst. Growth 92128

Savadogo O and Mandal K C 1992 Solar Energy Mater. Solar Cells 26117

Tong W, Wagner B K, Tran T K and Ogle W 1996 J. Cryst. Growth 164202

Ubale A U and Kulkarni D K 2005 Bull. Mater. Sci. 2843 